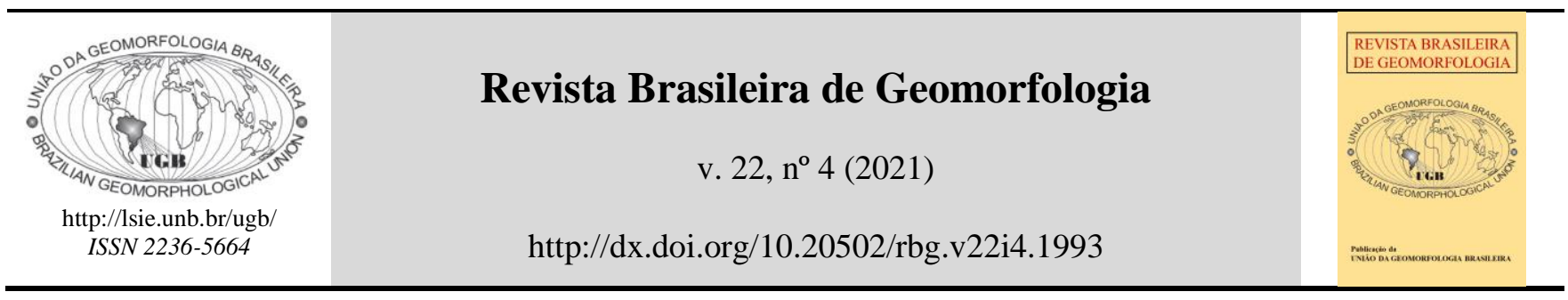

Nota técnica

\title{
Relevo brasileiro nos livros didáticos: equívocos e lacunas na representação em mapas e perfis topográficos
}

\author{
Brazilian relief in textbooks: misunderstandings and gaps in \\ representation in maps and topographic profiles
}

\author{
Alexandre dos Santos Souza1, Max Furrier ${ }^{2}$ \\ 1 Universidade Estadual da Paraíba, Departamento de Geografia, Campina Grande - PB, Brasil. E-mail. alesougeo@gmail.com \\ ORCID: https://orcid.org/0000-0003-4670-0734 \\ 2 Universidade Federal da Paraíba, Departamento de Geociências, João Pessoa - PB, Brasil. E-mail. max.furrier@gmail.com \\ ORCID: https://orcid.org/0000-0001-8882-5290
}

Recebido: 23/07/2020; Aceito: 01/07/2021; Publicado: 01/10/2021

\begin{abstract}
Resumo: Livros didáticos de Geografia abordam informações de caráter geomorfológico desde as primeiras séries do Ensino Fundamental, mas é na 1ํㅗㄹ Série do Ensino Médio que se observa maior ênfase. O presente trabalho tem por objetivo analisar o conteúdo que trata especificamente sobre o relevo do Brasil nos 14 livros didáticos aprovados e distribuídos pelo Plano Nacional do Livro Didático (PNLD) para o triênio 2018/2020. A proposta é avaliar as informações utilizadas na abordagem do conteúdo, identificando as bases conceituais, bem como a qualidade dos componentes imagéticos aplicados na apresentação da temática. Observou-se nos livros didáticos avaliados a necessidade urgente de correções e atualizações de conceitos, e ausência de informações relevantes sobre o quadro geomorfológico do Brasil. Como propostas para resolução de vários problemas encontrados, foram consultadas fontes bibliográficas especializadas e atualizadas. Também foi proposto a utilização do software Google Earth para elaboração de perfis topográficos dos compartimentos de relevo do Brasil. Trabalhos nessa linha são importantes pois buscam contribuir com o ensino de um tema fundamental para o entendimento da configuração das paisagens brasileiras, um conhecimento necessário aos alunos e à sociedade.
\end{abstract}

Palavras-chave: Geomorfologia do Brasil; Ensino de Geomorfologia; Classificação do Relevo.

\begin{abstract}
Geography textbooks address geomorphological information since the first grades of Elementary School, but it is in the 1st grade of High School that the greatest emphasis is observed. This research aims to analyze the content that deals specifically with the relief of Brazil in the 14 textbooks approved and distributed by the Plano Nacional do Livro Didático (PNLD) for the 2018/2020 triennium. The proposal is to evaluate the information used to approach the content, identifying the conceptual bases, as well as the quality of the image components applied in the presentation of the subject. It was observed in the textbooks evaluated the urgent need for corrections and updates of concepts, and absence of relevant information about the geomorphological framework of Brazil. As proposals for solving several problems found, specialized and updated bibliographic sources were consulted. It was also proposed to use Google Earth software to prepare topographic profiles of relief compartments in Brazil. Researches along these lines are important as they seek to contribute to the teaching of a fundamental theme for understanding the configuration of Brazilian landscapes, a necessary knowledge for students and society.
\end{abstract}

Keywords: Geomorphology of Brazil; Geomorphology teaching; Relief classification. 


\section{Introdução}

O estudo do relevo traz possibilidades e desafios para o ensino de Geografia na Educação Básica. Possibilidades porque, quando se estudam os aspectos morfológicos do relevo, pretende-se, entre tantas coisas possíveis, desenvolver noções básicas fundamentais acerca de dinâmicas que ocorrem em ambientes naturais (geologia, clima, bacias hidrográficas, solos etc.), bem como sobre as formas de uso e ocupação do espaço geográfico pela atividade antropogênica. Já os desafios surgem quando se consideram os recursos, os métodos e as diversas peculiaridades conceituais necessárias para se trabalhar o tema, que requer conhecimentos específicos da Geografia Física, muitas vezes precariamente ensinada em cursos de Licenciatura em Geografia.

Nessa perspectiva, é fundamental encontrar meios de ensino que não sejam meramente abstratos, principalmente porque, na Educação Básica, esse conhecimento é majoritariamente disponibilizado no livro didático. Por isso, o presente trabalho tem por finalidade avaliar, nos 14 livros didáticos de Geografia da 1aㅗ Série do Ensino Médio distribuídos pelo Plano Nacional do Livro Didático (PNLD) 2018/2020 (BRASIL, 2017), se o conteúdo sobre o relevo do Brasil se apresenta com informações condizentes com o nível do ensino escolar, uma vez que abordagens muito tradicionais, demasiadamente técnicas, descritivas, desatualizadas e até mesmo equivocadas tendem a dificultar o aprendizado por parte do alunado comprometendo o ensino.

Neste sentido, Oliveira (2010) considera que o ensino de Geomorfologia ainda é uma área pouco estudada, não obstante sua importância no livro didático de Geografia. Ora, se isso ainda é um fato no âmbito acadêmico, que dirá no nível da Educação Básica? Por essa razão, avigora-se a necessidade de desenvolvimento de pesquisas direcionadas a melhorar as possibilidades e os instrumentos utilizados no ensino dessa área do conhecimento.

Algumas contribuições estudaram a problemática sobre o relevo brasileiro em livros didáticos, analisando o conteúdo, os conceitos, a significância do ensino sobre o relevo nos estudos geográficos, bem como a necessidade de discussão e aprimoramento da temática nesses livros (FACHINELLO; CANDIDO; ROSATO, 2000), (BERTOLINI; VALADÃO, 2009), (SOUZA; VALADÃO, 2013), (MENEGUZZO; MENEGUZZO, 2014), (SANTOS; LUIZ, 2019). Para Bertoloni e Carvalho (2015), é importante ensinar sobre o relevo na escola básica a partir de abordagens particulares: em diferentes escalas e por meio de recursos didáticos e metodologias adequadas, visando melhorar o ensino aprendizagem da geomorfologia e consequentemente da própria geografia.

Nesse entendimento, Rezende e Vieira (2021) ressaltam a necessidade de aprofundamento de temáticas das Geociências no ensino básico através da utilização das ferramentas do Google Maps e Google Earth, através das quais é possível a observação em 3D das formas de relevo em diferentes escalas. Além disso, quando disponíveis, tais ferramentas permitem visualização de fotografias, elaboração de perfis topográficos, delimitação de áreas e trajetos, entre outros, abrindo possibilidades interessantes de estudo e de entendimento das paisagens.

De acordo com Ross (1999), não se deve estudar o relevo apenas visando definir a distribuição geográfica das formas e dos processos. Este autor, no ano de 1985, publicou na Revista do Departamento de Geografia da USP o artigo Relevo brasileiro: uma nova proposta de classificação, alertando para o fato de os livros didáticos de Geografia se mostrarem desatualizados nas questões inerentes ao relevo do Brasil e, naquele contexto, continuarem espelhando informações da geomorfologia do Brasil a partir de dados obtidos na década de 1940 (ROSS, 1985). Surge assim o questionamento que norteia este trabalho: como se apresenta atualmente o relevo brasileiro nos livros didáticos de Geografia?

Para Suertegaray (2000), o estudo do relevo pode contribuir significativamente com o reconhecimento de peculiaridades dos espaços de vivência onde os seres humanos desenvolvem suas atividades, à medida que ocupam as paisagens terrestres. Como bem coloca Ross (1990, p. 10), "o relevo terrestre é parte importante do palco, onde o homem, como ser social, pratica o teatro da vida". 
Sendo assim, o presente trabalho se direciona a avaliar, nos livros didáticos, aspectos qualitativos e quantitativos das informações, identificando as tendências conceituais e a pertinência do tema. A questão merece total atenção, porque, no ensino de Geografia escolar, não se deve trabalhar o relevo do Brasil de forma meramente descritiva, conteudista, desatualizada e sem explorar as possibilidades de ensino-aprendizagem próprias da Educação Básica; afinal, a temática envolve conhecimentos que são úteis ao desenvolvimento de noções básicas para o exercício das relações sociedade/natureza.

\section{A importância do estudo do relevo e o livro didático como recurso de ensino}

No ensino de Geografia na Educação Básica, é importante observar a qualidade das informações apresentadas para abordar o estudo sobre as formas do relevo. Nesse sentido, ressalta-se a necessidade de analisar se na apresentação dos conteúdos são identificadas as particularidades que, em muitos casos, estão distantes do cotidiano do alunado (LANDIME; BARBOSA, 2011).

O conhecimento das características físicas do relevo terrestre possui importância fundamental para a construção do espaço geográfico, ou seja, o estudo das paisagens geomorfológicas permite entender melhor propriedades físicas dos lugares onde os seres vivos realizam suas atividades (BERTOLINI; VALADÃO, 2009).

Trabalhos desenvolvidos por Dodick e Orion (2003), Kali; Orion; Eylon (2003), Souza (2015), e Souza e Furrier (2020), investigando os conteúdos e a qualidade das informações sobre Ciências da Terra em livros didáticos (mais precisamente no campo da Geologia), ressaltaram a importância do ensino de temáticas físico-naturais no Ensino Básico, o que, de certa forma, provoca o interesse do direcionamento de outros trabalhos semelhantes no campo da Geomorfologia, neste caso em particular, sobre o relevo do Brasil.

O primeiro relato sobre a paisagem geomorfológica do Brasil está registrado na Carta de Pero Vaz de Caminha, quando, ao avistar terra firme, fez o relato "dum grande monte, mui alto e redondo; e doutras serras mais baixas ao sul dele; e de terra chã, com grandes arvoredos: ao monte alto o capitão pôs nome - o Monte Pascoal [...]" (CAMINHA, 1500, p. 1). Naquele momento, a noção do explorador português se limitou ao deslumbre da beleza cênica da paisagem costeira. Aquela visão empírica, em primeiro plano, foi incapaz de abarcar a escala de grandeza, tampouco a diversidade de formas e recursos naturais presentes no território avistado.

Obviamente, para consolidar os interesses de exploração do território, era necessário conhecer as características físico-naturais dos ambientes. Com o passar do tempo, as particularidades do relevo brasileiro foram classificadas e catalogadas por renomados estudiosos da época. Alexander Von Humboldt, por exemplo, em sua expedição em terras hoje brasileiras, reuniu esforços destinados a corrigir informações apresentadas em mapas elaborados por seus antecessores (ANDRÄ, 1962). Entretanto, apesar da relevância dos registros históricogeográficos realizados inicialmente sobre a peculiaridade das paisagens do território brasileiro, as informações não foram suficientes para abarcar em detalhes a variedade de paisagens geomorfológicas do atual território do Brasil.

Nesse ínterim, surgiram os núcleos de povoamento e a sociedade do período colonial se estabeleceu, havendo, assim, necessidade de implantação de diversos serviços, entre eles o ensino escolar. A educação praticada a partir do início do século XIX era destinada a acolher os grupos seletos da elite, e adotou a linha das edições de livros elaborados em conformidade com os padrões europeus, sem a preocupação de adequá-los à realidade das classes mais pobres do país (SOARES, 1993), (ZACHEU; CASTRO, 2015).

Diante desse cenário, os trabalhos de Miguel Delgado de Carvalho foram pioneiros na elaboração de livros didáticos que rompiam com os formatos meramente descritivos centrados na memorização. Os esforços de Carvalho são reconhecidos como elos que estimularam o ensino de Geografia na educação escolar brasileira (PETRONE, 1993; ABREU, 2006). Barros (2008) e Vlach (1989) também destacam o papel dos trabalhos de Carvalho 
como escritor de manuais didáticos e na difusão do pensamento geográfico no Brasil, notadamente para o conceito de região e regionalização do Brasil.

Já Azambuja (2014, p. 15) ressalta os trabalhos de Aroldo de Azevedo dedicados à Geografia escolar brasileira, cuja produção didática foi marcada "pela consolidação do paradigma a Terra e o Homem". De acordo com Santos (1984), a produção de Aroldo de Azevedo atingiu a marca de 30 títulos de livros didáticos destinados a todas as modalidades da educação do período entre os anos de 1936 e 1975, ultrapassando a marca dos 12 milhões de exemplares comercializados.

Para Fachinello, Cândido e Rossato (2000), os estudos sobre o relevo em livros didáticos seguiram o perfil de abordagem desenvolvido a partir dos trabalhos de Aroldo de Azevedo, durante os anos de 1940, que classificou o relevo a partir da altitude; e de Aziz Nacib Ab'Sáber, a partir de 1958, que classificou o relevo observando os processos de formação geológica e modelagem das estruturas. Nesse sentido destaca-se o livro "A obra de Aziz Nacib Ab'Sáber" na qual Modenesi-Gauttieri et al. (2010) reuniu os trabalhos desse expoente geógrafo e geomorfólogo brasileiro que produziu um vasto acervo científico dedicado ao estudo das paisagens do Brasil, com destaque para o relevo.

As classificações supracitadas foram bastante usuais durante meados do século XX, até que, entre os anos de 1970 e 1985, imagens de radar e elaboração de cartas topográficas com escala de detalhe obtidas pelo Projeto RADAMBRASIL permitiram que Jurandyr Luciano Sanches Ross, geógrafo e professor da Universidade de São Paulo (USP), elaborasse um mapa cuja taxonomia demonstrou, com maior riqueza de detalhes, as características dos grandes compartimentos de relevo do Brasil, bem como seu embasamento geológico simplificado (ROSS, 1985, 1998). O resultado dos trabalhos de Ross possibilitou ampliar para 28 o número de unidades do relevo, antes classificado por Ab'Sáber em apenas 10 unidades (FACHINELLO; CÂNDIDO; ROSSATO, 2000).

Atualmente, o conteúdo que trata de geomorfologia nos livros didáticos é abordado com maior ênfase em

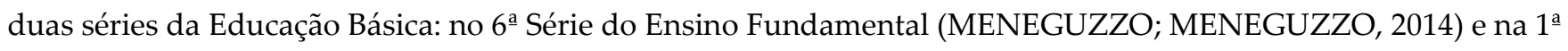
Série do Ensino Médio, conforme observado nas coleções distribuídas pelo PNLD 2018/2020 (BRASIL, 2017), cujos livros foram selecionados no presente trabalho (Quadro 1).

Quadro 1. Livros didáticos do 1ํㅗㄹ Série do Ensino Médio ofertados pelo PNLD 2018

\begin{tabular}{|c|c|c|c|c|}
\hline LD & Título/Editora & Ano/Edição & Autores & Cap. \\
\hline 1 & Ser Protagonista Geografia - SM & $2016-3^{a}$ & $\begin{array}{c}\text { Bianca Carvalho Vieira; Carla Bilheiro Santi; Carlos Henrique } \\
\text { Jardim; Fernando dos Santos Sampaio; Flávio Manzatto de } \\
\text { Souza; Ivone Silveira Sucena; André Baldraia. }\end{array}$ & 7 \\
\hline 2 & $\begin{array}{l}\text { Geografia: Contextos e Redes - } \\
\text { Moderna }\end{array}$ & $2016-2^{a}$ & Angela Corrêa Da Silva; Nelson Bacic Olic; Ruy Lozano. & 8 \\
\hline 3 & Geografia Geral e do Brasil - Scipione & $2016-3^{a}$ & Eustáquio De Sene; João Carlos Moreira. & 6 \\
\hline 4 & Geografia no Cotidiano - Base Editorial & $2016-1^{\mathrm{a}}$ & Dadá Martins; Francisco Bigotto; Márcio Vitiello. & 5 \\
\hline 5 & Geografia: Leituras e Interação - Leya & $2016-2^{a}$ & Antonio Luís Joia; Arno Aloísio Goettems. & 5 \\
\hline 6 & $\begin{array}{c}\text { Geografia: espaço e identidade - } \\
\text { Do Brasil }\end{array}$ & $2016-1^{a}$ & Andressa Alves; Levon Boligian. & 14 \\
\hline 7 & Geografia em Rede - FTD & $2016-2^{a}$ & Edilson Adão; Laercio Furquim Jr. & 6 \\
\hline 8 & Fronteiras da Globalização - Ática & $2016-3^{a}$ & Lúcia Marina Alves de Almeida; Tércio Barbosa Rigolin. & 7 \\
\hline 9 & Geografia das Redes - Do Brasil & $2016-3^{a}$ & Douglas Santos. & 5 \\
\hline 10 & $\begin{array}{l}\text { Território e Sociedade no Mundo } \\
\text { Globalizado - Saraiva Educação }\end{array}$ & $2016-3^{a}$ & $\begin{array}{c}\text { Anselmo Lazaro Branco; Cláudio Mendonça; Elian Alabi } \\
\text { Lucci. }\end{array}$ & 6 \\
\hline 11 & $\begin{array}{c}\text { Conexões: estudos de Geografia Geral } \\
\text { e do Brasil - Moderna }\end{array}$ & $2016-3^{a}$ & Lygia Terra; Raul Borges Guimarães; Regina Araujo. & 10 \\
\hline 12 & $\begin{array}{c}\text { Geografia: ação e transformação - } \\
\text { Escala Educacional }\end{array}$ & $2016-1^{a}$ & Alice de Martini, Rogata Soares Del Gaudio & 4 \\
\hline 13 & Vivá Geografia - Positivo & $2016-1^{a}$ & Igor Moreira & 5 \\
\hline 14 & Contato Geografia - Quinteto & $2016-1^{a}$ & Rogério Martinez e Wanessa Garcia & 4 \\
\hline
\end{tabular}

Nota: LD1 faz parte da única coleção que declarou possuir autor com formação em Geografia Física. 
Vale salientar que na 1ํㅗㄹ Série do Ensino Médio, não apenas o relevo, mas diversos outros ramos das Ciências da Terra são apresentados nos livros didáticos, os quais têm sido submetidos à análise dos conteúdos em trabalhos desenvolvidos por Carneiro, Toledo e Almeida (2004); Carneiro, Mizusaki e Almeida (2005); Toledo (2005); Souza e Furrier (2020); Souza, Furrier e Lavor (2021). A importância do ensino das Ciências da Terra no currículo escolar também é abordada em outros países. Na Espanha, por exemplo, Pedrinaci et al. (2013) apresentam conhecimentos básicos e conceitos considerados relevantes para alfabetização em Ciências da Terra.

Nessa perspectiva, o estudo do relevo brasileiro a partir de livros didáticos de Geografia deve ser tratado com a devida importância, uma vez que permite refletir, de forma interdisciplinar, acerca de diversas outras temáticas e dinâmicas ambientais ocorridas nas paisagens naturais e antropogênicas. Por isso, torna-se importante analisar cuidadosamente se os livros didáticos são desprovidos de erros e apresentam informações que não sejam meramente conteudistas, fragmentadas, desatualizadas e distantes da escala da percepção e vivência dos estudantes e dos próprios professores.

No que tange ao tratamento dado às informações sobre os conteúdos geomorfológicos presentes nos livros didáticos da 1ํㅗ Série do Ensino Médio, notam-se alguns problemas, entre eles: a grande variedade de formas e detalhes que evidentemente não podem ser representadas em sua totalidade num livro didático; aspectos que envolvem o acesso a bibliotecas, Internet e demais equipamentos necessários para o ensino, os quais muitas vezes, não estão acessíveis aos alunos e professores de muitas regiões remotas e pobres do Brasil.

Para Bittencourt (2004), o livro didático tem sido objeto de debates no universo escolar, na academia, em congressos e em periódicos científicos, nos quais estão envolvidos autores, editoras e intelectuais de diversas áreas. Conclui-se que o livro didático é relevante objeto de pesquisa, ao abrir possibilidades de análise sobre a organização, a qualidade e a profundidade dos conteúdos abordados no processo de escolarização.

Nessa perspectiva, é relevante desenvolver trabalhos que ampliem a compreensão do livro didático como um dos principais instrumentos na produção de planos de ensino dos conteúdos ministrados na sala de aula, principalmente quanto às características do relevo, um tema que envolve peculiaridades fundamentais para desenvolvimento das atividades humanas sobre as paisagens terrestres.

\section{Resultados e discussões}

\subsection{O que dizem os livros didáticos sobre o relevo do Brasil}

Para avaliação do conteúdo sobre o relevo brasileiro nos livros didáticos (LDs) aprovados para o PNLD 2018/2020, observaram-se, em cada livro, o capítulo e o tópico específico que trata da questão (conforme Quadro 1). Algumas informações que remetem às formas do relevo brasileiro são comumente encontradas nos livros didáticos (LDs) analisados em diversos capítulos que não tratam especificamente do estudo do relevo, por exemplo: no capítulo sobre cartografia, nos tópicos sobre as categorias de análise geográfica, estruturas do relevo terrestre, questões ambientais, bacias hidrográficas, entre outros.

Segundo Mendonça (1992), alguns autores "geógrafos" com formação em áreas da denominada Geografia Humana retratam nos livros didáticos diversos aspectos de temáticas físico-naturais, sem passar por um revisor científico de Geografia Física ou de Geociências. Esse quadro pode contribuir para abordagens superficiais e, muitas vezes, erradas sobre o relevo.

Outra questão percebida na apresentação do conteúdo sobre o relevo do Brasil nos livros analisados se assemelha às observações feitas por Almeida, Araújo e Mello (2015), ao destacarem a forma como temas da Geologia são predominantemente retratados nos livros didáticos, dando ênfase a ilustrações de caráter global, em 
muitos casos com pouca ênfase a exemplos regionais, característica também observada nos livros de Geografia analisados neste trabalho, no que tange às informações sobre as formas de relevo do Brasil.

Observou-se que, nos capítulos que tratam particularmente da temática do relevo brasileiro, são utilizados majoritariamente mapas temáticos e/ou, em menor quantidade, mapas hipsométricos, além de fotos, perfis topográficos e desenhos esquemáticos (Figura 1). A utilização dos elementos supracitados é claramente assimétrica nos livros didáticos analisados, em que predominam as fotografias (mesmo que insuficientes) para retratar as principais unidades do relevo.

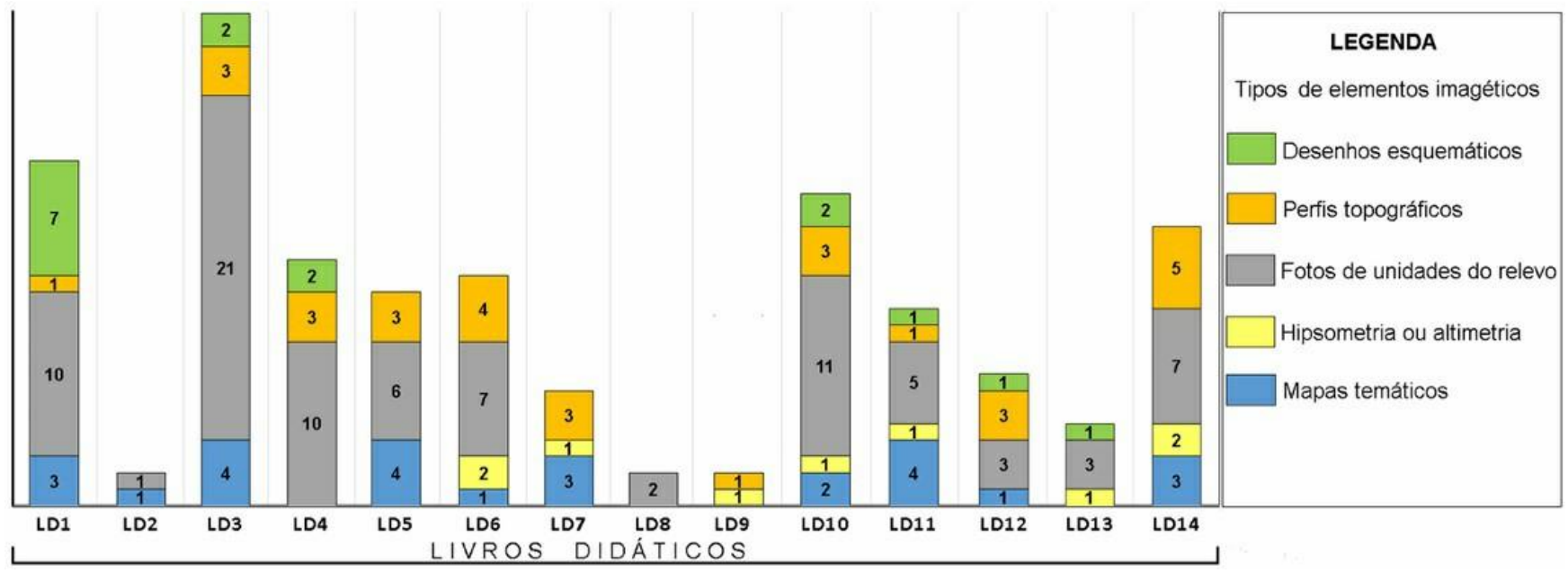

Figura 1. Quantificação das informações imagéticas utilizadas nos livros didáticos analisados.

\subsection{Classificação do relevo em mapas temáticos}

Quanto aos mapas de classificação do relevo, averiguou-se a presença das classificações propostas por Aroldo de Azevedo, Ab'Sáber e Jurandyr Ross, sendo este último utilizado com maior frequência. Dos 14 livros analisados, 10 apresentam a classificação de Ross (Figura 2a, 2b) e 4 (LD4, LD8, LD9, LD10 e LD13) não apresentam qualquer mapa de classificação referente aos autores supramencionados, embora o LD8, apesar de não apresentar mapa de classificação, faz breve menção textual à classificação do relevo proposta por Jurandyr Ross.

$\mathrm{Na}$ classificação do relevo brasileiro apresentada nos livros didáticos analisados, observam-se dados ultrapassados quando comparada à classificação proposta por Ross (1985). Em alguns livros ainda se apresenta a classificação proposta por Aroldo de Azevedo de 1940 que, para Ross (1985), apesar da importância, é uma classificação superada, não havendo a necessidade de ser apresentada em detalhe nos livros didáticos, exceto quando se pretende enfatizar aspectos da evolução histórica do conhecimento.

Obviamente, todos os trabalhos pretéritos realizados no esforço de caracterização do relevo brasileiro merecem o devido crédito e respeito, afinal, representam os resultados possíveis de se alcançar diante dos recursos e condições técnicas e tecnológicas disponíveis no tempo em que foram realizados. Entretanto, considerando os avanços e os dados produzidos no Projeto RADAMBRASIL (BARBOSA et al., 1984), com o uso de imagens de radar, aerolevantamento e trabalhos de campo, foi possível alcançar uma escala de detalhe maior das unidades do relevo do Brasil, ampliando de 10 para 28 o número de compartimentos geomorfológicos.

Desta forma, diante das vastas possibilidades de utilização de novas tecnologias como recurso didático de ensino, defende-se que as antigas classificações sejam utilizadas apenas em casos que se pretenda contextualizar diferentes abordagens realizadas ao longo da história, pois, os avanços obtidos a partir do Projeto RADAMBRASIL 
e o emprego das novas tecnologias possibilitam estudar as características do relevo com um nível muito maior de detalhe.

Nesta perspectiva, em virtude de tais progressos, tem-se no trabalho de classificação de Jurandyr Ross uma base de informações mais precisas para retratar em livros didáticos da Educação Básica, porque sintetiza com maior precisão a realidade do cenário geomorfológico do Brasil para o contexto no qual foi elaborada. Entretanto, considerando-se a realidade de uma abordagem didática e direcionada, compatível com o ensino escolar, é fundamental que essas informações, na medida em que sejam adaptadas, passem por um rigoroso processo de refinamento que permita a compreensão do alunado e o aprendizado sem equívocos.

Vale salientar que, os recursos tecnológicos disponíveis atualmente na internet de forma gratuita, como por exemplo, o Google Earth e Google Maps, podem colaborar em muito no aprendizado do aluno, bem como facilitar o trabalho do professor na explicação desse conteúdo, além de poder mostrar aos alunos como é o relevo de sua cidade, de sua comunidade e de sua escola, ou seja, mostrar o relevo regional e local do cotidiano de cada aluno. A interação entre o livro didático e o Google Earth no ensino do relevo regional não foi abordada em nenhum livro didático analisado. A possibilidade de popularização do conhecimento sobre o relevo através de ferramentas disponíveis na Internet é apresentada por Rezende e Vieira (2021) como um procedimento didático acessível que pode ser aplicado no ensino de Geociências e consequentemente no ensino do relevo brasileiro.

\subsection{Principais equívocos encontrados}

Nos livros didáticos, observam-se muitas cópias e adaptações realizadas do mapa do relevo brasileiro proposto por Ross (1998), todavia, sem qualquer atualização significativa e, em muitos casos, com erros crassos de identificação e localização de unidades do relevo e de seus componentes litológicos. Na elaboração dos mapas temáticos, os autores dos livros didáticos adotaram técnicas de semiologia cartográfica com variável visual em cores e hachuras para destacar os compartimentos geomorfológicos. Apesar de todos utilizarem a classificação proposta por Ross (conforme Figura 2a e 2b), não há homogeneidade entre os mapas temáticos apresentados.

Nos LD1, LD10 e LD14 inseriram-se os limites dos estados da federação e a rede hidrográfica dos principais rios brasileiros; nos LD2 e LD7 inseriram-se apenas os limites estaduais; e no LD11 inseriu-se somente a hidrografia. No LD12 observa-se uma peculiaridade em que a planície do rio Amazonas se apresenta numa escala discrepante dos outros mapas - inclusive da classificação original proposta por Ross -, ou seja, a referida planície se estendeu para outros rios da região (Figura $2 a, 2 b$ ). 


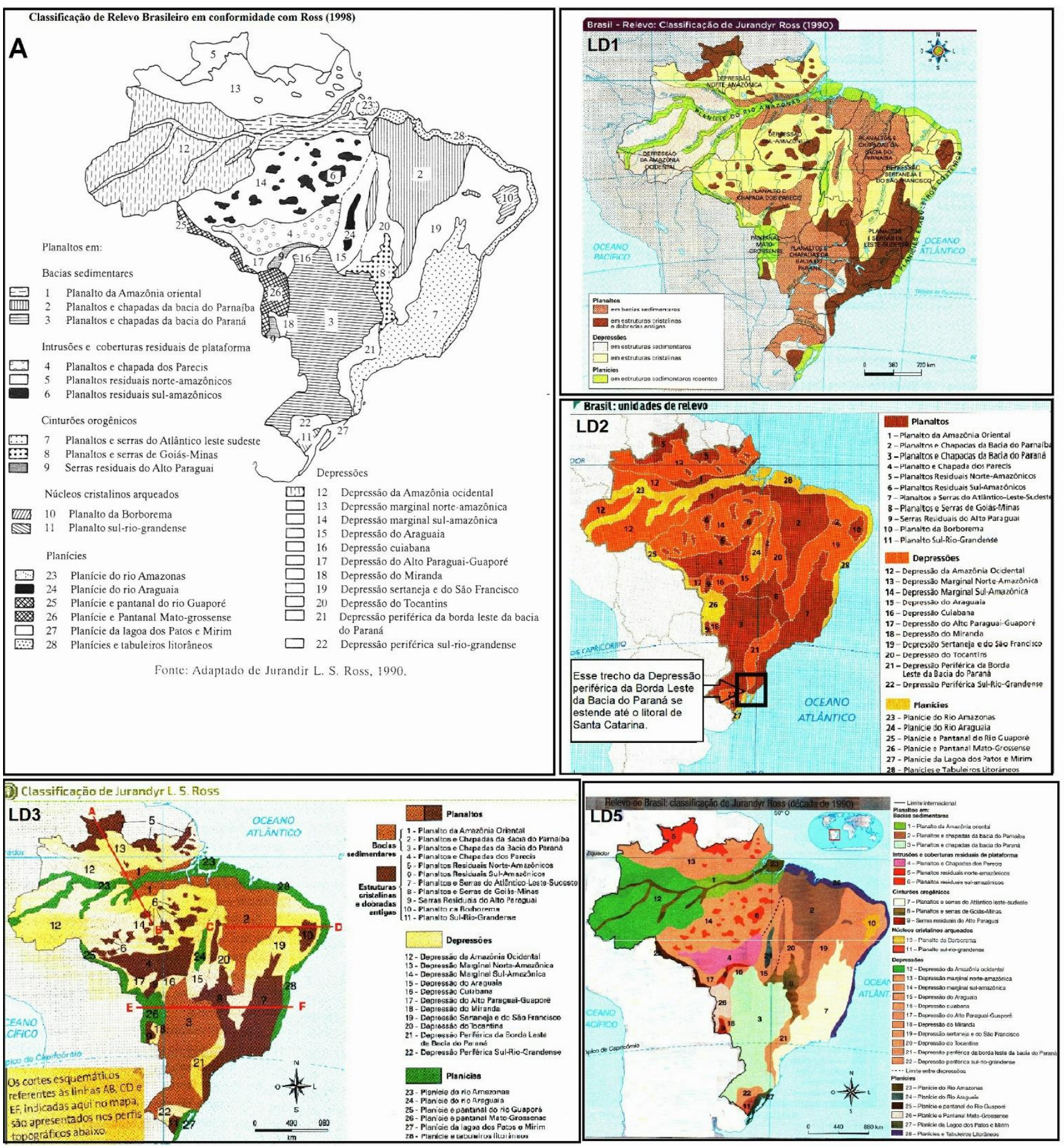

Figura 2a. Mapas temáticos utilizados nos livros didáticos analisados.

Um equívoco grave se observa no LD2 e LD11, nos quais se indicou, nos respectivos mapas, a extremidade meridional da Depressão Periférica da Borda Leste da Bacia do Paraná - a qual se estende até o litoral de Santa Catarina - em contato com a porção setentrional da Planície da Lagoa dos Patos e Mirim, no estado do Rio Grande do Sul (Figura 2a, 2b). 

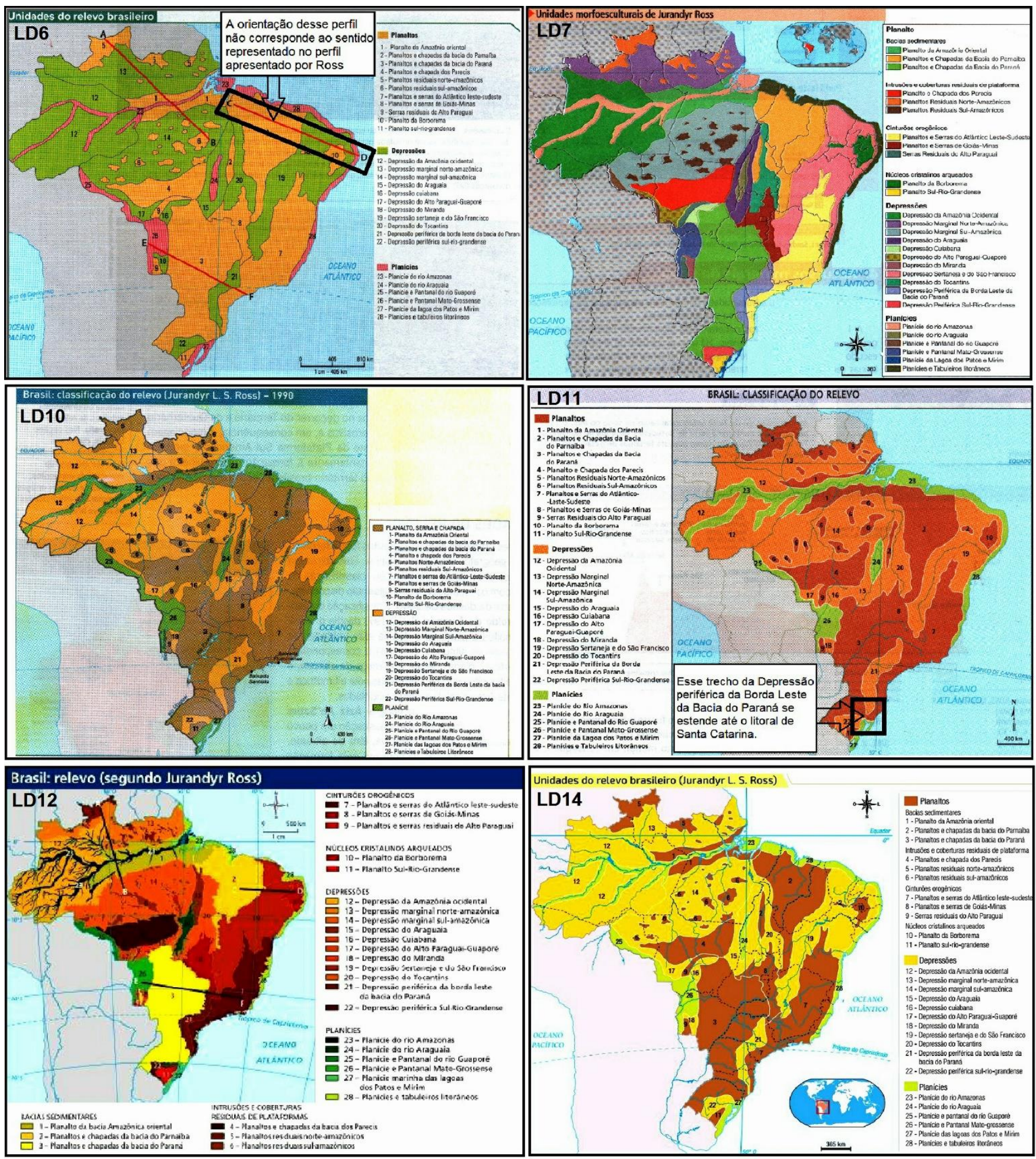

Figura 2b. Mapas temáticos utilizados nos livros didáticos analisados.

\subsection{Caracterização do relevo a partir de perfis topográficos}

A utilização dos perfis topográficos também se fundamenta nos modelos escalares apresentados por Ross (1998), com adaptação visual para identificação de alguns compartimentos geomorfológicos correspondentes a terrenos cristalinos e sedimentares (Figura 3). 
Um problema que deve ser observado nas representações sobre o relevo por meio de perfis topográficos é a questão do exagero vertical, principalmente quando a distância da área representada é muita extensa, como é o caso dos perfis elaborados por Ross e reproduzidos nos livros didáticos. A extensão longitudinal ultrapassa os $1.000 \mathrm{~km}$ em todos os perfis traçados. Nesse caso, se não for adotado exagero vertical as formas menos acentuadas do relevo serão representadas completamente aplainadas.
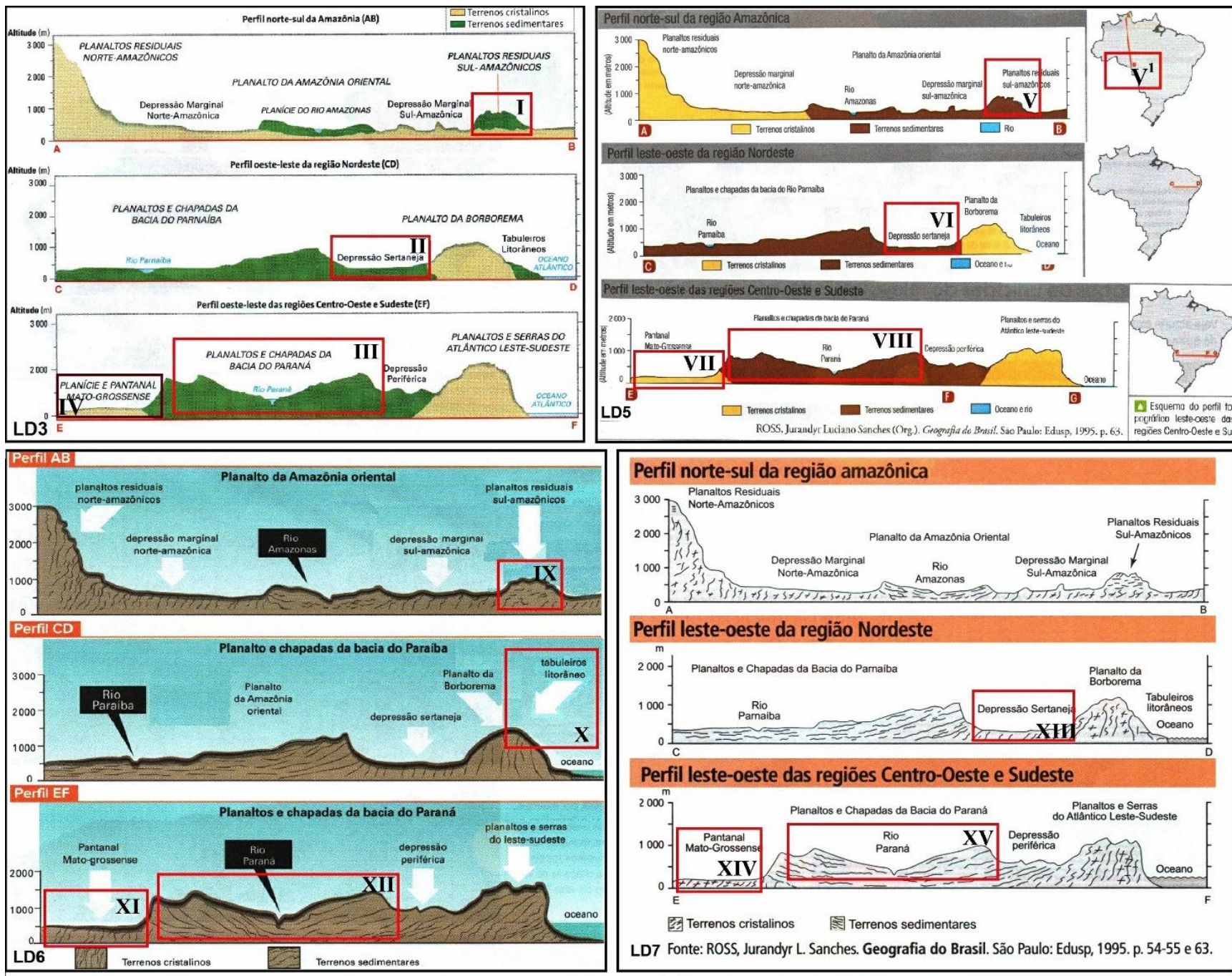

\section{Perfil leste-oeste da região Nordeste}
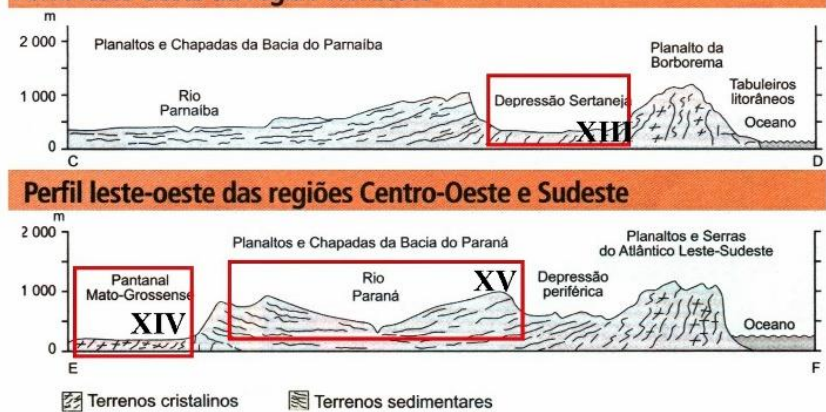

LD7 Fonte: ROSS, Jurandyr L. Sanches. Geografia do Brasil. São Paulo: Edusp, 1995. p. 54-55 e 63.
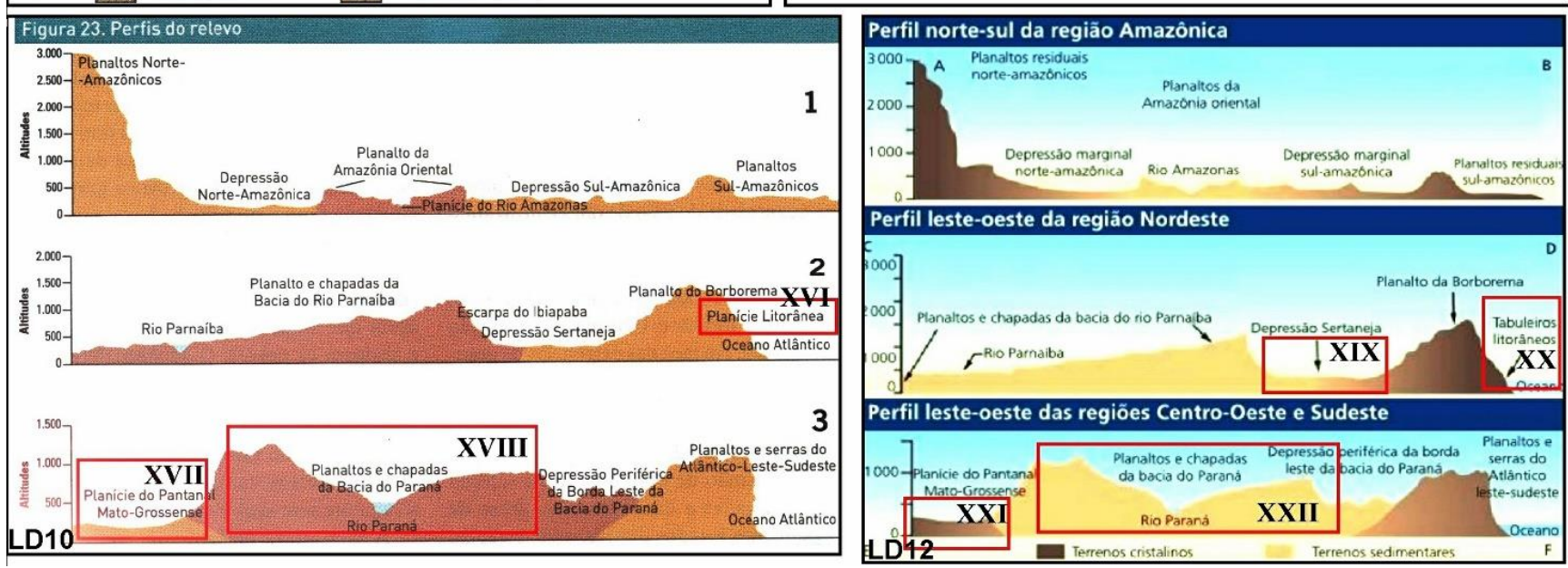

Figura 3. Identificação dos equívocos presentes na elaboração dos perfis topográficos analisados. 
O uso do exagero vertical para realçar a morfologia nos perfis torna-se inevitável em representações do relevo em escala pequena, todavia, esse exagero não pode ser demasiadamente discrepante e sempre que presente deverá ser explicado. Essa característica pode ser vista como uma possibilidade de levar o estudante a encontrar maneiras de equacionar as relações de escala entre a distância e a altitude, fato que pode ser mais bem esclarecido por meio do uso de ferramentas gratuitas como o Google Earth Pro, no qual, de acordo com Gomes et al. (2008) é possível incrementar o ensino do relevo por meio da observação tridimensional, ampliando a percepção espacial do estudante. Outro recurso didático que pode ser aplicado visando incrementar o ensino de geomorfologia é a confecção de modelos escalares de maquetes (MAURI et al., 2021). Estes procedimentos ampliam as possibilidades de se estudar o relevo.

Nas adaptações realizadas em muitos perfis topográficos apresentados nos livros didáticos, constam equívocos gravíssimos que destoam da realidade das características litológicas dos terrenos indicados, fato que compromete significativamente a compreensão e a aprendizagem sobre o tema. Entre os principais equívocos, destacam-se:

a) A classificação de terrenos sedimentares para os Planaltos Residuais Sul-Amazônicos (I, V, IX) (Figura 3), sendo que, de acordo com Ross (1985), essas unidades do relevo são representadas por áreas pontilhadas de intrusões graníticas dentro do Cráton do Amazonas, sendo, portanto, terreno cristalino.

b) A atribuição de terreno sedimentar para o embasamento da Depressão Sertaneja (II, VI, XIII, XIX) (Figura 3), quando na região, segundo Ross (1985), há ocorrência de inselbergues associados a unidades litológicas cristalinas.

c) Indicação de terreno cristalino para o trecho correspondente à Planície do Pantanal MatoGrossense (IV, VII, XI, XIV, XVII, XXI) (Figura 3), contrariando drasticamente a composição litológica desse terreno, que, segundo Ross (1985), representa uma área de deposição recente de sedimentos aluviais. Chama a atenção esse grave erro repetir-se em seis livros didáticos. Uma vez que o perfil está errado no próprio livro de Ross (1998), fonte de todos os perfis encontrados nos livros didáticos, tratase, portanto, de cópias de fonte com erro, não identificada pelos autores e nem pelos revisores destes livros didáticos.

d) No trecho correspondente aos Planaltos e Chapadas da Bacia do Paraná (III, VIII, XII, XV, XVIII, XXII) (Figura 3), reproduziu-se o entendimento de que a composição litológica da região é um embasamento exclusivamente sedimentar, sem qualquer indicação do vulcanismo fissural ocorrido na área que constitui a Formação Serra Geral (WILDNER; ORLANDI FILHO; GIFFONI, 2004) que é constituída principalmente por basaltos. Ross (1985) menciona rochas vulcânicas máficas que abrangem extensa área da região centro-sul do Brasil se estendendo ao longo das fronteiras do Paraguai, Uruguai e Argentina. Foram reconstruídos neste trabalho os 3 perfis presentes em Ross (1998) e utilizados nos livros didáticos. Os perfis foram construídos com a ajuda do software Google Earth e ajustados às unidades litológicas gerais de cada área sendo inferido também o embasamento cristalino conforme será demonstrado na Figura 4.

e) No perfil A-B (norte-sul da região amazônica) presente em LD5 (Figura 3), a indicação V1 no mapa do ponto B foi colocada na região definida por Ross (1985) como Chapada dos Parecis, localizada ao norte do Mato Grosso e ao sudeste de Rondônia, cujo trecho não é contemplado no perfil.

f) Nos trechos (X e XX) dos perfis apresentados em LD6 e LD12 (Figura 3), os Tabuleiros Litorâneos (substrato sedimentar) estão indicados no topo do Planalto da Borborema (terreno cristalino). Neste caso, a escala de representação inviabiliza a indicação dos Tabuleiros Litorâneos, não apenas pela 
diferenciação litológica, mas também pelo aspecto geomorfológico. Erro semelhante se constata no trecho destacado (XVI) de LD10, no qual se indicou a planície costeira no setor da escarpa oriental do Planalto da Borborema.

Considerando todos esses equívocos que foram e vêm sendo reproduzidos nos livros didáticos analisados, conclui-se que a abordagem feita por meio de perfis é claramente desprovida de tratamento científico, técnico e didático, pois retrata, muitas vezes de forma errônea, as unidades litológicas dos terrenos representados, comprovando que, no item em questão, não foi consultada qualquer outra bibliografia especializada sobre as respectivas áreas. A conclusão parece ser válida não apenas nas obras analisadas neste trabalho, mas em muitos outros que não são distribuídos pelo PNLD, que são de conhecimento destes autores por terem trabalhado em escolas privadas.

Destarte, considerando a enorme quantidade de erros verificados e a necessidade de correção desses erros nos livros didáticos analisados, foram elaborados para este trabalho perfis topográficos detalhados de trechos correspondentes àqueles apresentados por Ross (1998) e replicados nos referidos livros didáticos, esperando-se que no futuro esta nota técnica possa ser fonte de referência e de consulta técnica para professores e autores de livros didáticos. Os perfis elaborados neste trabalho foram baseados em trabalhos de Ross (1985; 1998); Santos, Ferreira e Silva (2002), Araújo (2015), Ferreira, Bastos e Luparelli (2015) e Morelatto (2017).

Entretanto, além de trabalhos técnicos consultados que permitem ilustrar corretamente a composição litológica genérica dos terrenos, também se utilizou a ferramenta do Google Earth para traçar os perfis topográficos. Na elaboração dos perfis (Figura 4) foi observada através do software Google Earth, a localização exata dos pontos onde seriam traçados os perfis. É importante destacar que esse procedimento não foi executado em nenhum dos perfis apresentados nos livros didáticos analisados, os quais se detiveram apenas a reproduzir - com algumas modificações - os perfis ilustrativos apresentados por Ross (1998), sem fornecer informações claras para que os leitores reflitam sobre a questão da relação entre a distância do terreno representado e o exagero vertical desse tipo de representação, que inevitavelmente impossibilita a observação de unidades taxonômicas menores existentes que compõem o relevo.

Visando uma abordagem mais adequada e interdisciplinar sobre ensino de geomorfologia na Educação Básica a partir dos livros didáticos e das novas tecnologias, apresentam-se na Figura 4, perfis topográficos, nos quais foram realizadas adequações e inseridos dados para poder ilustrar com mais detalhes aspectos de extensas áreas que recobrem o relevo brasileiro, conforme informações expostas no eixo horizontal dos perfis A, B e C (Figura 4). Neste caso, os produtos elaborados (Figura 4), também apresentam, além das informações sobre a distância do terreno, dados relativos à altitude, permitindo refletir sobre a questão do exagero vertical, que nos exemplos dados são de aproximadamente: $95 \mathrm{X}$ no perfil A; $101 \mathrm{X}$ no perfil B; e $80 \mathrm{X}$ no perfil C. Esse fato precisa ser explicado e observado por docentes e discentes quando utilizarem elementos imagéticos com esse nível de escala de representação. Constam também dados de coordenadas geográficas que podem ser utilizadas para localização no software Google Earth dos pontos escolhidos para traçar os perfis e a partir desse procedimento, levar o estudante a observar em 3D, formas que não podem ser representadas a partir do perfil topográfico. As informações apresentadas permitem abordar durante as aulas, aspectos do relevo, da geologia, da cartografia, da geografia, entre outras características das paisagens.

Na elaboração dos perfis A, B e C (Figura 4) foram ilustrados didaticamente não apenas aspectos morfológicos, mas, também, da composição litológica geral, como, por exemplo, as zonas hipotéticas de contato entre terrenos cristalinos e sedimentares, características não apresentadas anteriormente em qualquer livro didático. 


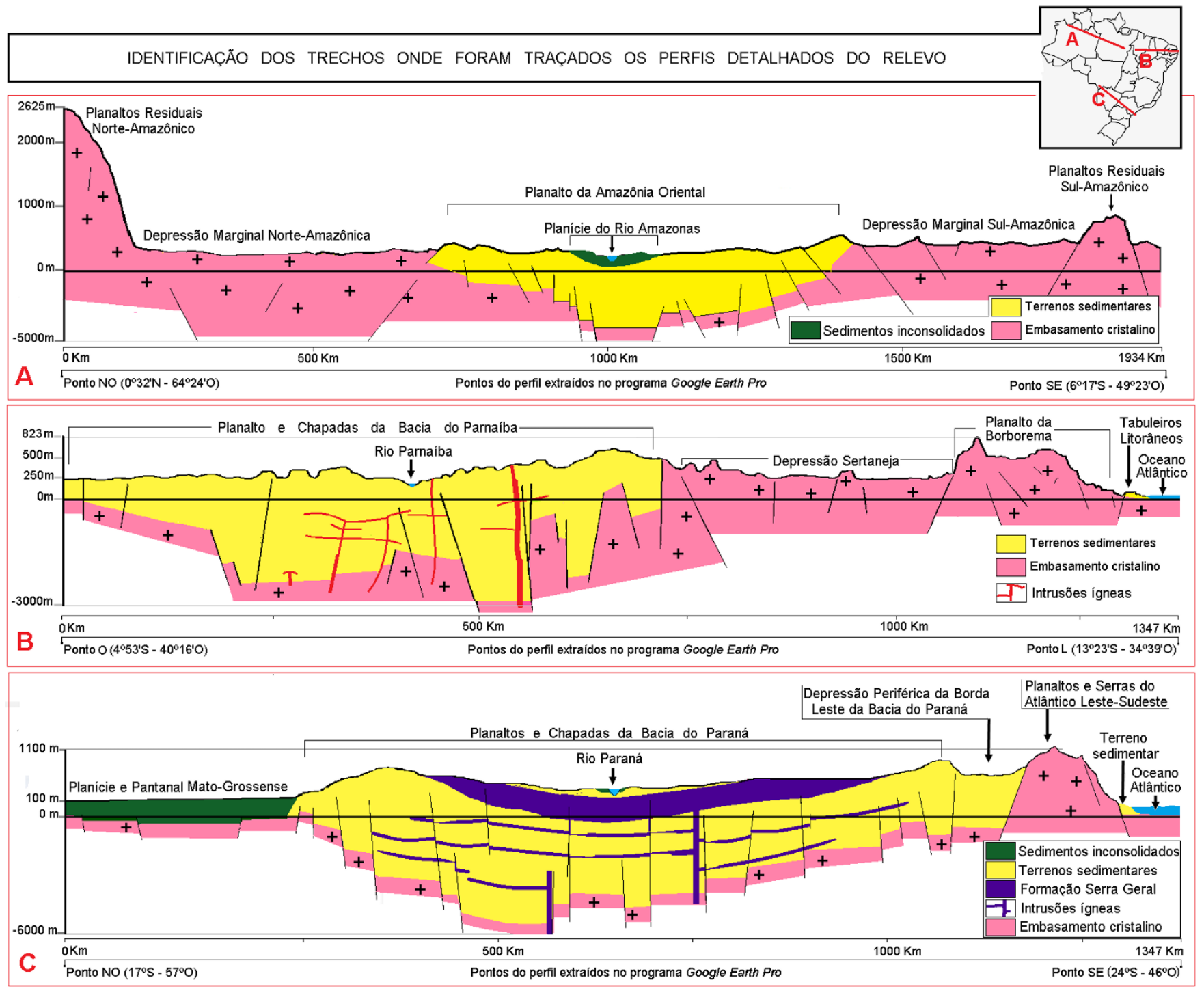

Figura 4. Perfis topográficos elaborados para os trechos dos perfis apresentados por Ross (1998).

Elaboração: Alexandre Souza e Max Furrier.

Os relevos esculpidos sobre terrenos sedimentares como, por exemplo: Planaltos e Chapadas da Bacia do Paraná (ROSS, 1985), foram desenvolvidos sobre bacias sedimentares. Em nenhum perfil topográfico dos livros didáticos é colocada a informação, o que inviabiliza o entendimento do termo bacia sedimentar que faz parte da denominação desse compartimento do relevo. Desta forma, faz-se necessário demonstrar que, no Brasil, todas as bacias sedimentares possuem um embasamento cristalino conforme ilustrado da figura 4 .

Cabe ressaltar que os aspectos relacionados à profundidade das litologias e do embasamento cristalino são ilustrativos e foram inferidos sem precisão, haja vista que esse tipo de informação não é assunto do Ensino Médio, contudo, os dados altimétricos da escala gráfica apresentados em cada perfil correspondem aos parâmetros reais observados nos trabalhos técnicos supracitados e utilizando o Google Earth, os quais foram adaptados de forma mais didática para o Ensino Médio.

Em virtude da gratuidade e acessibilidade do software Google Earth, pode haver ampliação significativa, no ambiente escolar, da compreensão dos estudantes sobre a morfologia do relevo mediante a criação de vídeos, visualização em 3D, verificação e diferenciação de escala e localização. A consulta ao Google Earth, quando 
acessível em escolas com acesso à Internet, cria formas didáticas e interessantes de estudo, possibilitando valorizar e ampliar a importância do ensino sobre o relevo do Brasil na Educação Básica.

\section{Conclusões}

Os livros didáticos representam importantes instrumentos norteadores do ensino utilizados nas escolas públicas brasileiras, por isso, é imprescindível que o processo de elaboração, escolha, aquisição e distribuição dos livros didáticos receba a devida atenção por parte dos agentes responsáveis. Dados do Fundo Nacional de Desenvolvimento da Educação (BRASIL, 2020a), registram que no triênio de 2018/2019/2020 foram distribuídos 452.561.559 exemplares de livros didáticos destinados a todas as etapas da Educação Básica, totalizando um gasto de mais de $\mathrm{R} \$ 3.960 .000 .000,00$, sendo considerado o maior programa de distribuição de livros didáticos do mundo.

Este trabalho revela a urgência de se desenvolver pesquisas especializadas direcionadas ao estudo dos conteúdos sobre o relevo brasileiro em livros didáticos, não apenas de Geografia, mas também de outros componentes curriculares, de maneira que os conteúdos possam ser apresentados de forma propositiva, atualizada e desprovida de equívocos, levando ao público-alvo informações claras, úteis e corretas.

Observa-se que, apesar dos progressos obtidos em trabalhos pretéritos, não há necessidade de, no âmbito do Ensino Básico, utilizar classificações como as apresentadas por Aroldo de Azevedo nos anos de 1940, exceto para ilustrar a história do conhecimento. Os avanços obtidos com o Projeto RADAMBRASIL e a classificação do relevo apresentada por Ross trouxeram maior clareza e detalhamentos das principais unidades de relevo do Brasil. Cabe sim, melhorar a qualidade do livro didático referente a esse assunto e propor novos métodos e técnicas de aprendizagem que suplantem a memorização simplista e completamente ineficaz na compreensão do relevo brasileiro pelos alunos da Educação Básica.

Uma evidência obtida neste trabalho foi que alguns autores dos livros didáticos não consultaram com rigor o trabalho original que propôs uma nova divisão do relevo brasileiro (ROSS, 1985). Seis livros didáticos, de um conjunto de 14, replicaram o erro que consta no livro Geografia do Brasil (ROSS, 1998). Embora no perfil original apresentado no trabalho de Ross (1998) constar a informação equivocada de que o compartimento do relevo denominado Planície e Pantanal Mato-grossense é composto por rochas cristalinas, no texto do mesmo livro a informação é detalhada de forma correta pelo autor enfatizando que a Planície e Pantanal Mato-grossense possui litologia sedimentar.

A análise sobre o conteúdo do relevo brasileiro nos livros didáticos distribuídos pelo PNLD apresentada nesse trabalho reforça a necessidade indiscutível de melhoria das informações apresentadas e de uma seleção mais criteriosa na escolha das obras, pois, apesar dos elevados investimentos destinados ao processo de aquisição dos livros didáticos, comprovou-se a necessidade de efetuar correções de conteúdo e uma melhoria na abordagem conceitual adaptada à realidade do ensino escolar.

Contribuições dos Autores: Análise dos livros didáticos, revisão bibliográfica, organização dos dados e elaboração das figuras, Alexandre dos Santos Souza; Redação do texto, Alexandre dos Santos Souza e Max Furrier. Revisão e orientação: Max Furrier. Os autores leram e concordaram com a versão publicada do manuscrito

Financiamento: Esta pesquisa foi financiada pelo Programa de Demanda Social - DS da Coordenação de Aperfeiçoamento de Pessoal de Nível Superior (CAPES), bolsa n 88887. 482334/2020-00 por meio do Programa de Pós-Graduação em Geografia (PPGG) da Universidade Federal da Paraíba - Campus João Pessoa -PB.

Agradecimentos: O autor principal reconhece os esforços da Coordenação de Aperfeiçoamento de Pessoal de Nível Superior (CAPES) na concessão de bolsa de Doutorado. Os autores agradecem ao Instituto Federal de Educação, Ciência e Tecnologia 
da Paraíba, Campus Cabedelo, que doou os livros didáticos analisados neste trabalho. Os autores também agradecem os avaliadores por todas as relevantes contribuições que corroboraram com a melhoria deste trabalho.

Conflito de Interesse: Declaramos não haver conflito de interesse. Não existiu nenhuma interferência no desenvolvimento do estudo por parte dos apoiadores da pesquisa. Todas as etapas de construção deste trabalho foram realizadas com a total liberdade e responsabilidade dos autores.

\section{Referências}

1. ABREU, M. Pierre Monbeig e os primórdios da geografia urbana no Brasil. In: SALGUEIRO, H. (Org.). Pierre Monbeig e a geografia humana brasileira. Bauru: EdUSC, 2006. p. 129-160. ISBN: 9788574603148

2. ALMEIDA, C. N.; ARAÚJO, C.; MELLO, E. F. Geologia nas escolas de Ensino Básico: a experiência do Departamento de Geologia da Universidade Federal do Rio de Janeiro. Terræ Didatica, v. 11, n. 3, p. 150-161, 2015. DOI: 10.20396/td.v11i3.8643643 3. ANDRÄ, H. Alexander von Humboldt e as suas relações com o Brasil. Revista de História, v. 25, n. 52, p. 387-403, 1962. DOI: 10.11606/issn.2316-9141.rh.1962.121720

4. ARAÚJO, D. B. Bacia do Parnaíba. Brasília: ANP; SDP, 2015. Disponível em: < $\underline{\text { https://pt.slideshare.net/ANPgovbr/bacia- }}$ do-parnaba-51512346>. Acesso em: 20 jan. 2020.

5. AZAMBUJA, L. D. O livro didático e o ensino de Geografia do Brasil. Revista Brasileira de Educação em Geografia, v. 4, n. 8, p. 11-33, 2014. Disponível em: <http://www.revistaedugeo.com.br/ojs/index.php/revistaedugeo/article/view/180> Acesso em: 20 jul. 2020. ISSN: 2236-3904

6. $\quad$ BARBOSA, G. V.; SILVA, T. C. NATALI FILHO, T.; DEL'ARCO, D. M.; COSTA, R. C. R. Evolução da metodologia para mapeamento geomorfológico do Projeto RADAMBRASIL. Boletim Técnico Projeto RADAMBRASIL. Série Geomorfologia,

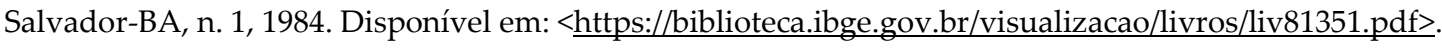

7. BARROS, N. C. C. Delgado de Carvalho e a Geografia no Brasil como arte da educação liberal. Estudos Avançados, v. 22, n. 62, p. 317-333, 2008. DOI: 10.1590/S0103-40142008000100021

8. BRASIL. Ministério da Educação. Fundo Nacional de Desenvolvimento da Educação. Programas do livro: PNLD - dados estatísticos. Brasília: MEC/FNDE, 2020a. ISSN: 0102-2873

9. BERTOLINI, W. Z. O ensino de relevo: noções e propostas para uma didática da geomorfologia. Dissertação (Mestrado em Geografia e Análise Ambiental) - Universidade Federal de Minas Gerais, Belo Horizonte, 2010. 174p.

10. BERTOLINI, W. Z.; CARVALHO, V. L. M. Abordagem da escala espacial no ensino aprendizagem do relevo. Terrae Didatica, Campinas, SP, v. 6, n. 2, p. 58-66, 2015. DOI: 10.20396/td.v6i2.8637452

11. BERTOLINI, W. Z.; VALADÃO, R. C. A abordagem do relevo pela geografia: uma análise a partir dos livros didáticos. Terræ Didatica, v. 5, n. 1, p. 27-41, 2009. DOI: 10.20396/td.v5i1.8637500

12. BITTENCOURT, C. M. F. Apresentação. Educação e Pesquisa, v. 30, n. 3, p. 471-473, 2004. DOI: 10.1590/S151797022004000300007

13. BRASIL. Ministério da Educação. PNLD 2018: Geografia - guia de livros didáticos - Ensino Médio. Brasília: MEC/SEB/FNDE, 2017.

14. CAMINHA, P. V. A Carta de Pero Vaz de Caminha. Brasília: Fundação Biblioteca Nacional, 1 maio 1500. Disponível em: <http://objdigital.bn.br/Acervo Digital/livros eletronicos/carta.pdf $>$. Acesso em: 10 jan. 2020.

15. CARNEIRO, C. D. R.; MIZUSAKI, A. M. P.; ALMEIDA, F. F. M. A determinação da idade das rochas. Terræ Didatica, v. 1, n. 1, p. 6-35, 2005. DOI: 10.20396/td.v1i1.8637451

16. CARNEIRO, C. D. R., TOLEDO, M. C. M. de; ALMEIDA, F.F.M. de. 2004. Dez motivos para a inclusão de temas de Geologia na Educação Básica. Revista Brasileira de Geociencias. V. 34, n. 4, p. 553-560. DOI: 10.25249/0375-7536.2004344553560 
17. CPRM - SERVIÇO GEOLÓGICO DO BRASIL. Radam-D. Disponível em: <http://www.cprm.gov.br/publique/Geologia/Sensoriamento-Remoto-e-Geofisica/RADAM-D-628.html>. Acesso em: 10 fev. 2020.

18. DODICK, J.; ORION, N. Measuring student understanding of geological time. Science Education, v. 87, p. 708-731, 2003. DOI: 10.1002/sce.1057

19. FACHINELLO, A.; CÂNDIDO, L. A.; ROSSATO, M. S. O relevo brasileiro nos livros didáticos, uma questão a ser repensada. Boletim Gaúcho de Geografia, v. 26, n. 1, p. 74-82, 2000.

20. FERREIRA, A. L.; BASTOS, G.; LUPARELli, A. Bacia do Amazonas. Brasília: ANP; SDP, 2015. Disponível em: <https://pt.slideshare.net/ANPgovbr/bacia-do-amazonas $>$. Acesso em: 05 jan. 2020.

21. GOMES, J. V. P.; SOARES, J. G.; MENDONÇA, A. A. I.; BARROS, R. S. de. In: Simpósio Nacional de Geografia Física (2008). As potencialidades do MDE para o Ensino de Geografia Física. Disponível em: <http://www.geomorfologia.ufv.br/simposio/simposio/trabalhos/trabalhos completos/eixo6/012.pdf >. Acesso em: 15 fev. 2020. 22. LANDIM, F. O.; BARBOSA, M. E. S. O ensino de geografia na educação básica: uma análise da relação entre a formação do docente e sua atuação na geografia escolar. Geosaberes, v. 1, n. 2, p. 160-179, 2011. Fortaleza, v. 1, n. 2, p. 160-179, jan. 2011. ISSN 2178-0463

23. KALI, Y.; ORION, N.; EYLON, B. S. Effect of knowledge integration activities on students' perception of the Earth's crust as a cyclic system. Journal of Research in Science Teaching, v. 40, n. 6, p. 545-565, 2003. DOI: 10.1002/tea.10096

24. MAURI, S.; SCHETTINO, V. R.; MARQUES, R. de A.; SOARES, C. C. V.; GOUVÊA, L. P. Confecção de maquetes geológicas: o exemplo da Serra do Caparaó (Minas Gerais e Espírito Santo, Brasil). Terrae Didatica, Campinas, SP, v. 17, n. 00, p. e021002, 2021. DOI: 10.20396/td.v17i00.8661553

25. MENDONÇA, F. Geografia Física: ciência humana? 3. ed. São Paulo: Contexto, 1992. 72p. ISBN: 9788585134419

26. MENEGUZZO, I. S.; MENEGUZZO, P. M. O relevo terrestre nos livros didáticos de Geografia do $6^{0}$ ano do Ensino Fundamental. Revista Didática Sistêmica, v. 16, n. 1, p.21-31, 2014. ISSN: 1809-3108

27. MODENESI-GAUTTIERI, M.C.; BARTORELLI, A.; MANTESSO NETO, V.; CARNEIRO, C.D.R.; LISBOA, M.A. (orgs.) 2010. A obra de Aziz Nacib Ab'Sáber. São Paulo: Ed. Beca. 588p. ISBN: 97885-62768-05-7

28. MORELATTO, R. Bacia do Paraná: sumário geológico e setores em oferta. Brasília: ANP SDB, 2017. Disponível em: <http://rodadas.anp.gov.br/arquivos/Round15/Mapas/Sumario_Geologico R15 Parana.pdf >. Acesso em: 10 jul. 2020.

29. OLIVEIRA, A. O. S. A. Contribuição teórico-metodológica para o ensino de Geomorfologia. Tese (Doutorado em Geografia) - Universidade Estadual Paulista Júlio de Mesquita Filho, Presidente Prudente, 2010. 299p.

30. PEDRINACI, E.; ALCALDE, S.; ALFARO, P.; ALMODÓVAR, G. R.; BARRERA, J. L.; BELMONTE, Á; BRUSI, D.; CALONGE, A.; CARDONA, V.; CRESPO-BLANC, A.; FEIXAS, J. C.; FERNÁNDEZ-MARTÍNEZ, E. M.; GONZÁLEZ-DÍEZ, A.; JIMÉNEZ-MILLÁN, J.; LÓPEZ-RUIZ, J.; MATA-PERELLÓ, J. M.; PASCUAL. J. A.; QUINTANILLA, L.; RÁBANO, I.; REBOlLO, L.; RODRIGO, A., \& ROQUERO, E. Alfabetización en Ciencias de la Tierra. Rev. de la Enseñanza de las Ciencias de la Tierra, 21(2):117-129, 2013. ISSN: 1132-9157

31. PETRONE, P. O ensino de Geografia nos últimos 50 anos. Revista Orientação, n. 10, p. 3-17, 1993. Disponível em: <https://repositorio.usp.br/item/000871099>. Acesso em: 02 fev. 2020.

32. REZENDE, L. C. de; VIEIRA, A. C. B. Geogle Maps: google maps como ferramenta de ensino de geociências. Terrae Didatica, Campinas, SP, v. 17, n. 00, p. e021003, 2021. DOI: 10.20396/td.v17i00.8661509

33. ROSS, J. L. S. (Org.). Geografia do Brasil. 2. ed. São Paulo: EdUSP, 1998. ISBN: 85-314-0242-5

34. ROSS, J. L. S. Geomorfologia: ambiente e planejamento. São Paulo: Contexto, 1990. ISBN: 978-85-85134-82-2

35. ROSS, J. L. S. Relevo brasileiro: planaltos, planícies e depressões. In: CARLOS, A. F. A. (Org.). Novos caminhos da Geografia. São Paulo: Contexto, 1999. p. 41-63. (Coleção Caminhos da Geografia). ISBN: 978-85-7244-106-3 
36. ROSS, J. L. S. Relevo brasileiro: uma nova proposta de classificação. Revista do Departamento de Geografia, v. 4, p. 2539, 1985. DOI: 10.7154/RDG.1985.0004.0004

37. SANTOS, E. J. dos; FERREIRA, C. A.; SILVA JR., J. M. F. da (Orgs.). Geologia e recursos minerais do estado da Paraíba. Recife: CPRM, 2002. Disponível em: <http://rigeo.cprm.gov.br/jspui/handle/doc/5034>. Acesso em: 10 jan. 2020.

38. SANTOS, L. A.; LUIZ, E. L. Ensino dos conteúdos sobre relevo na Geografia Escolar: análise de uma coleção de livros didáticos dos anos finais do ensino fundamental. Geografia, v. 28, n. 2, p. 233-248, 2019. DOI: 10.5433/2447-1747.2019v28n2p233 39. SANTOS, W. A obra de Aroldo Azevedo: uma avaliação. Dissertação (Mestrado em Geociências) - Universidade Estadual Paulista Júlio de Mesquita Filho, Rio Claro, 1984. 99p.

40. SOARES, M. L. A. Diferentes propostas dos livros de Geografia e Estudos Sociais. Revista Orientação, n. 10, p. 61-71, 1993.

41. SOUZA, A. dos S.; FURRIER, M. Estudo da Escala do Tempo Geológico em livros didáticos de Geografia do ensino médio. Terræ Didatica, Campinas, SP, v. 16, artigo e020010, p. 1-15, 2020. DOI: 10.20396/td.v16i0.8656709

42. SOUZA, A. dos S.; FURRIER, M. Avaliação do conteúdo sobre estrutura interna da Terra em livros didáticos de Geografia do ensino médio de escolas públicas brasileiras. Revista do Departamento de Geografia, São Paulo, v. 40, p. 107-119, 2020. DOI: $10.11606 /$ rdg.v40i0.164834

43. SOUZA, A. dos S.; FURRIER, M.; LAVOR, L. F. de. Solos nos livros didáticos: contextualização e proposta de mapas didáticos. Terrae Didatica, Campinas, SP, v. 17, n. 00, e021010, p. 1-13, 2021. DOI: 10.20396/td.v17i00.8663686

44. SOUZA, C. J. O.; VALADÃO, R. C. Visualização e representação espaciais no ensino de Geomorfologia. Terræ Didatica, v. 9, n. 2, p. 105-113, 2013. DOI: 10.20396/td.v9i2.8637399

45. SOUZA, E. R. O potencial didático das imagens geocientíficas em livros de textos do ensino secundário: representação da dinâmica interna da Terra. Tese (Doutorado em Ciências) - Universidade Estadual de Campinas, Instituto de Geociências, Campinas, 2015. 524p. Disponível em: <http://repositorio.unicamp.br/jspui/handle/REPOSIP/286581> Acesso em: 02 fev. 2020. 46. SUERTEGARAY, D. M. A. O que ensinar em geografia (física)? In: Rego, n.; Suertegaray, D.; Heidrich, Á. (Orgs.). Geografia e Educação: geração de ambiências. Porto Alegre: Ed UFRGS, 2000. p. 97-106. ISBN: 8570255772

47. TOLEDO, M. C. M. Geociências no Ensino Médio brasileiro: análise dos Parâmetros Curriculares Nacionais. Geologia USP Publicação Especial, v. 3, p. 31-44, 2005. DOI: 10.11606/issn.2316-9087.v3i0p31-44

48. VLACH, V. R. F. Carlos Miguel Delgado de Carvalho e a “orientação moderna” em geografia. In: VESENTINI, J. W. (Org.). Geografia e ensino: textos críticos. Campinas: Papirus, 1989. p. 149-160. ISBN: 9788530800390

49. WILDNER, W.; ORLANDI FILHO, V.; GIFFONI, L. E. (Orgs.). Excursão virtual aos Aparados da Serra - RS/SC: Aspectos geológicos e turísticos dos Cânions do Itaimbezinho e Fortaleza: Formação Serra Geral. Porto Alegre: CPRM, 2004. Disponível em: $<$ http://sigep.cprm.gov.br/sitio050/sitio050.pdf $>$

50. ZACHEU, A. A. P.; CASTRO, L. L. O. Dos tempos imperiais ao PNLD: a problemática do livro didático no Brasil. In JORNADA DO NÚCLEO DE ENSINO, 14., 2015, Bauru. Anais [...] Bauru: Unesp, 2015.

Esta obra está licenciada com uma Licença Creative Commons Atribuição 4.0 Internacional (http://creativecommons.org/licenses/by/4.0/) - CC BY. Esta licença permite que outros distribuam, remixem, adaptem e criem a partir do seu trabalho, mesmo para fins comerciais, desde que lhe atribuam o devido crédito pela criação original. 